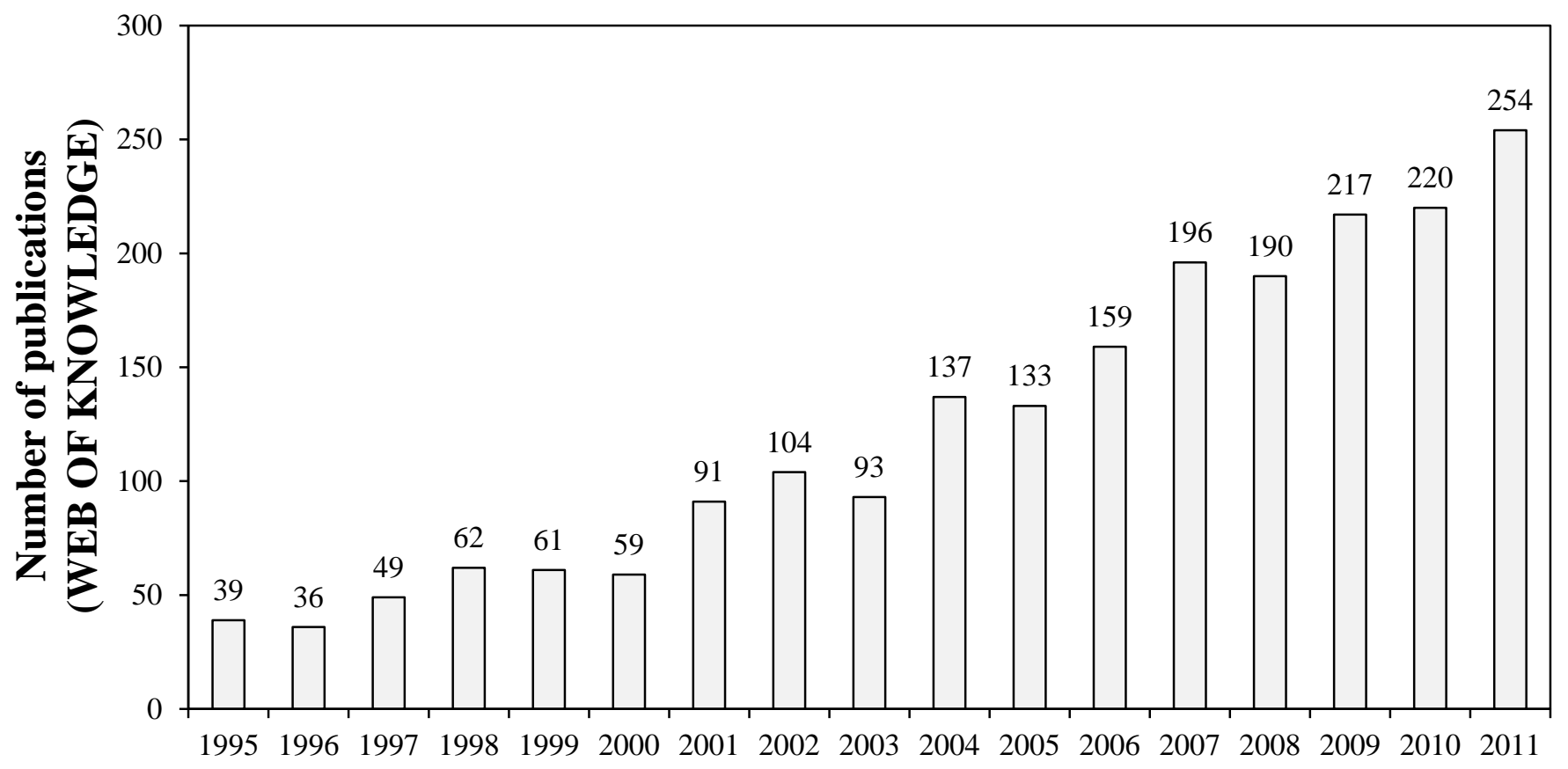

Figure S1 


\section{WEB OF KNOWLEDGE}

Sign In $\mid$ Marked List (0) | My EndNote Web | My ResearcherlD | My Journal List $\mid$ My Saved Searches $\mid$ Log Out $\mid$ Help

\section{Results Analysis}

$<<$ Back to previous page

2,100 records. Topic $=($ nicotiana benthamiana $)$

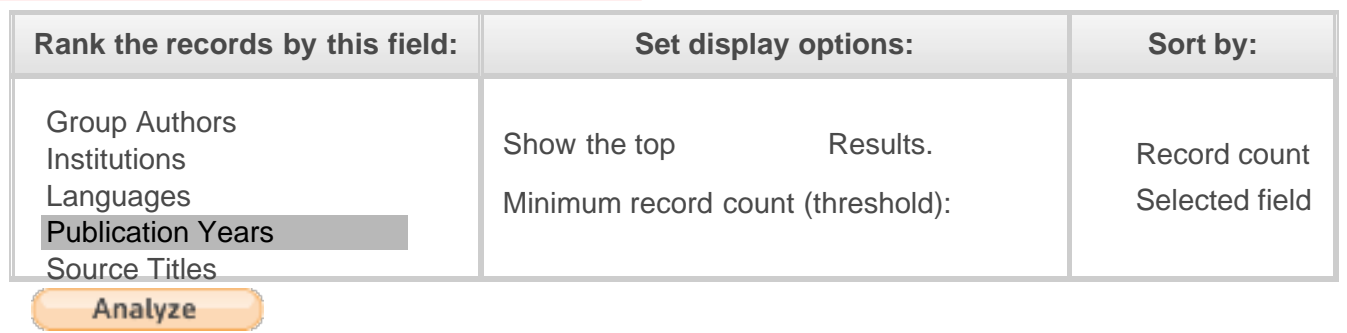

Use the checkboxes below to view the records. You can choose to view those selected records, or you can exclude them (and view the others).

\begin{tabular}{|c|c|c|c|c|c|}
\hline $\begin{array}{l}\rightarrow \text { View Records } \\
\times \text { Exclude Records }\end{array}$ & Field: Publication Years & Record Count & $\%$ of 2100 & Bar Chart & $\begin{array}{l}\text { Save Analysis Data to File } \\
\text { Data rows displayed in table } \\
\text { All data rows }\end{array}$ \\
\hline$\square$ & 1995 & 39 & $1.857 \%$ & I & \\
\hline$\square$ & 1996 & 36 & $1.714 \%$ & I & \\
\hline$\square$ & 1997 & 49 & $2.333 \%$ & I & \\
\hline$\square$ & 1998 & 62 & $2.952 \%$ & I & \\
\hline$\square$ & 1999 & 61 & $2.905 \%$ & I & \\
\hline$\square$ & 2000 & 59 & $2.810 \%$ & $\mathbf{I}$ & \\
\hline$\square$ & 2001 & 91 & $4.333 \%$ & $\square$ & \\
\hline$\square$ & 2002 & 104 & $4.952 \%$ & ! & \\
\hline$\square$ & 2003 & 93 & $4.429 \%$ & प & \\
\hline$\square$ & 2004 & 137 & $6.524 \%$ & 口 & \\
\hline$\square$ & 2005 & 133 & $6.333 \%$ & $\mathbf{\square}$ & \\
\hline$\square$ & 2006 & 159 & $7.571 \%$ & $\square$ & \\
\hline$\square$ & 2007 & 196 & $9.333 \%$ & $\mathbf{\square}$ & \\
\hline$\square$ & 2008 & 190 & $9.048 \%$ & $\square$ & \\
\hline$\square$ & 2009 & 217 & $10.333 \%$ & $\square$ & \\
\hline$\square$ & 2010 & 220 & $10.476 \%$ & $\square$ & \\
\hline$\square$ & 2011 & 254 & $12.095 \%$ & $\square$ & \\
\hline View Records & \multirow{2}{*}{ Field: Publication Years } & \multirow{2}{*}{ Record Count } & \multirow{2}{*}{$\%$ of 2100} & \multirow[b]{2}{*}{ Bar Chart } & Save Analysis Data to File \\
\hline$X$ Exclude Records & & & & & $\begin{array}{l}\text { Data rows displayed in table } \\
\text { All data rows }\end{array}$ \\
\hline
\end{tabular}

(c) 2012 Thomson Reuters | Terms of Use | Please give us your feedback on using Web of Knowledge. 